\title{
Estrutura fundiária das regiões Norte e Noroeste do Estado do Rio de Janeiro: 1972 a 1998
}

\author{
Paulo Marcelo de Souza* \\ Niraldo José Ponciano** \\ Henrique Tomé da Costa Mata***
}

Resumo - O trabalho procura verificar, a partir de informações das Estatísticas Cadastrais do INCRA, as alterações ocorridas na distribuição da posse da terra das regiões Norte e Noroeste fluminense, no período de 1972 a 1998. Para caracterizar a estrutura agrária dessas regiões, foram empregados o índice de Gini, a área média, o percentual da área correspondente aos $5 \%$ maiores imóveis e o percentual da área correspondente aos 50\% menores imóveis. Os resultados permitiram constatar diferenças significativas entre as regiões, com a região Norte sobressaindo-se por apresentar estrutura fundiária mais concentrada. Observou-se ainda que a estrutura fundiária dos municípios analisados sofreu poucas alterações no período.

Palavras-chave: estrutura fundiária, índice de Gini, distribuição da terra.

Classificação JEL: Q15

\footnotetext{
* Professor associado da Universidade Estadual do Norte Fluminense - UENF, Centro de Ciências e Tecnologias Agropecuárias - CCTA, Laboratório de Engenharia Agrícola/Setor de Economia Agrícola. pmsouza@uenf.br

**Professor associado da Universidade Estadual do Norte Fluminense - UENF, Centro de Ciências e Tecnologias Agropecuárias - CCTA, Laboratório de Engenharia Agrícola/ Setor de Economia Agrícola. ponciano@uenf.br

***É professor associado da Universidade Estadual de Santa Cruz - UESC, Departamento de Ciências Econômicas. hnrmata@uesc.br
} 
Abstract - The work has as objective to investigate, using data published by the Institute for Colonization and Land Reform (INCRA), the changes in land distribution in the North and Northwest regions of the Rio de Janeiro state, in the period from 1972 to 1998. The Gini index, the average area, the percentage of the area corresponding to the 5\% largest landholders, and the percentage of the area corresponding to the $50 \%$ smallest landholders, were used to describe the profile of the land distribution. The results show significant differences between the studied regions. Although both regions have a concentrated agrarian structure, the land distribution is worst in the North region. It was still observed that the agrarian structure of these regions has not presented significative changes in the period.

Key words: agrarian structure, Gini index, land distribution.

\section{JEL classification: Q15}

\section{Introdução}

A distribuição da terra no Brasil é historicamente concentrada, fato cuja origem remonta ao período da colonização, com as capitanias hereditárias e a doação das sesmarias. De origem histórica, essa estrutura concentrada tem se mantido ao longo dos anos, como revelam algumas análises (CUNHA, 2004, SOUZA e LIMA, 2003).

No Estado do Rio de Janeiro, a distribuição da posse da terra, conquanto menos concentrada que a média do país, apresenta-se ainda muito distante do que caracterizaria uma distribuição igualitária. Estudo realizado por HOFFMANN (1998), a partir de informações do Instituto Nacional de Colonização e Reforma Agrária (INCRA), revela que a distribuição da posse da terra nesse estado passou por algumas alterações no decorrer das últimas décadas, porém sem alterar significativamente sua conformação. Estimativas realizadas a partir de dados dos Censos Agropecuários evidenciam aumento do índice de Gini para o Rio de Janeiro no período de 1970 a 1985, passando de 0,790 a 0,816 (GASQUES E CONCEIÇÃO, 2003)

As regiões Norte e Noroeste do Rio de Janeiro representam, conjun- 
tamente, cerca de 35,3\% da área total do estado. De tradicional importância agrícola, essas regiões têm passado por um processo de empobrecimento, em parte associado às condições adversas do mercado de seus dois principais produtos, isto é, a cana-de-açúcar e o café1. Nesse contexto, a distribuição da terra nesses municípios pode ter sofrido alterações distintas das que foram observados para o estado como um todo, em virtude de suas condicionantes especificas. De todo o modo, além do efeito dessas condicionantes e das políticas e programas de cunho regional, com possíveis impactos sobre a distribuição da posse da terra, é esperado que essas regiões tenham sofrido os efeitos de políticas mais abrangentes, inseridas no contexto da política agrícola nacional. Esse é, possivelmente, o caso das políticas de modernização da agricultura brasileira, às quais se atribui a responsabilidade por importantes alterações na estrutura do setor agrícola.

Em particular, são destacados os efeitos do crédito rural subsidiado, uma das principais políticas voltadas para modernização da agricultura brasileira. Segundo MARTINE e BESKOW (1987), o crédito rural foi desigualmente distribuído entre regiões, entre tipos de produtos e entre classes de tamanho de produtores. Outras políticas, como os preços mínimos, o seguro rural e as políticas de subsídios, além de programas especiais de desenvolvimento regional, também atuaram no sentido de incentivar a concentração fundiária, além de beneficiar atividades e regiões específicas e favorecer a grande produção. GRAZIANO DA SILVA (1980) e CASTRO (1982) ressaltaram que, em virtude dos avanços das transformações capitalistas na agricultura e em resultado de políticas governamentais favorecendo as propriedades de grande porte e acarretando atraso nos pequenos estabelecimentos, a propriedade da terra tem-se tornado cada vez mais concentrada.

Inseridas no cenário agrícola nacional, as regiões Norte e Noroeste

\footnotetext{
${ }^{1}$ A produção de cana-de-açúcar na região Norte Fluminense retraiu-se nas últimas duas décadas, por efeito dos sucessivos planos econômicos, da extinção do IAA, da redução dos estímulos propiciados pelo PROÁLCOOL, bem como da baixa produtividade regional, fator de desvantagem num contexto de acirramento da competição com outras regiões (AZEVEDO, 2004). O cultivo do café, produto típico da região Noroeste, vem sofrendo os efeitos da queda nos preços, iniciada ao final da década de 1990, num cenário de estagnação do consumo mundial, oferta abundante e formação de estoques nos países importadores (SAES e NAKAZONE, 2002).
} 
fluminense sofreram o efeito das políticas de modernização agrícola, com possíveis impactos sobre sua estrutura fundiária. Partindo desse pressuposto, admite-se que o estudo dessas alterações, e a caracterização do atual perfil agrário dessas regiões, constitui-se em importante contribuição no sentido de fornecer subsídios à elaboração das políticas agrícolas, que não devem ser concebidas sem o reconhecimento e a consideração das especificidades regionais.

\section{Objetivos}

O trabalho tem como objetivo verificar, para os municípios das regiões Norte e Noroeste do Estado do Rio de Janeiro, as mudanças ocorridas na distribuição da posse da terra no período de 1972 a 1998. Tomando, como premissas, os possíveis impactos negativos das políticas voltadas para a modernização agrícola sobre a estrutura fundiária, espera-se que a distribuição da terra nesses municípios tenha se concentrado no período. Tal concentração deve ter afetado, sobretudo, os municípios da região Norte, em geral especializados na produção de cana-de-açúcar e, portanto, sujeitos aos impactos dos incentivos do Proálcool.

Há que se ressaltar que o trabalho tem natureza exploratória, visando verificar a ocorrência de mudanças na distribuição da posse da terra nos referidos municípios, bem como o sentido predominante dessas mudanças. Como limitação, o texto não aborda as causas dessas mudanças, nem seus possíveis impactos econômicos e sociais, em face do estágio inicial em que se encontram os estudos sobre esses municípios, dos quais ele é resultante.

\section{पाए etodologia e fonte de dados}

Para analisar as alterações na estrutura fundiária, foram calculados o índice de Gini, a área média, o percentual da área correspondente aos $50 \%$ menores imóveis e o percentual correspondente aos $5 \%$ maiores imóveis, que são normalmente usados como indicadores da distribuição da posse da terra. As informações necessárias ao cômputo dos indicadores da distribuição da terra foram obtidas das Estatísticas Cadastrais 
(1972, 1992 e 1998) e das Estatísticas Cadastrais Anuais (1989, 1990, 1991) do INCRA².

É necessário ainda tecer algumas considerações a respeito das mudanças na distribuição geográfica das regiões consideradas, alterada em função das emancipações ocorridas ao longo do período estudado. A região Norte encontra-se, atualmente, constituída pelos municípios de Campos dos Goytacazes, Cardoso Moreira, São Francisco de Itabapoana, São João da Barra, São Fidélis, Conceição de Macabu, Quissamã, Carapebus e Macaé. Já a região Noroeste corresponde aos municípios Porciúncula, Varre-Sai, Natividade, Itaperuna, Bom Jesus de Itabapoana, Itaperuna, Laje do Muriaé, Miracema, São José do Ubá, Santo Antônio de Pádua, Cambuci, Italva, Aperibé e Itaocara.

Durante o período analisado, vários dos municípios das regiões analisadas ainda não existiam. Esse é o caso dos municípios: VarreSai, emancipado de Natividade, em 1993; de Cardoso Moreira, emancipado em 1988, formado a partir de antigos distritos de Campos dos Goytacazes; Italva, fundada em 1986, tendo sido desmembrada de Campos dos Goytacazes; Quissamã, que se emancipou de Macaé em 1989; Carapebus, outrora distrito de Macaé, emancipado em 1995; Aperibé, emancipado de Santo Antônio de Pádua, em 1992; São Francisco do Itabapoana, que pertencera ao município de São João da Barra, do qual se emancipou em 1995; e, São José de Ubá, fundada em 1997, após separar-se de Cambuci. Por essa razão, não se dispõe de dados sobre a distribuição da terra nesses municípios mais recentes, para todo o período. Isso impossibilitou o cálculo dos indicadores para esses municípios, e contribuiu para dificultar a análise das mudanças ocorridas no período.

\footnotetext{
${ }^{2}$ Como as Estatísticas Cadastrais não divulgam dados individuais acerca da posse da terra, apresentando sua distribuição entre classes, o índice de Gini calculado termina por subestimar sua verdadeira desigualdade, uma vez que se desconhece a desigualdade existente dentro dos estratos ou classes de tamanho fornecido por esta publicação, como destacado por HOFFMANN (1979). Entretanto, não foram utilizados os procedimentos sugeridos para contornar essa limitação, uma vez que o objetivo maior da pesquisa é abordar a evolução da distribuição da posse da terra, não sendo o valor absoluto de sua concentração o aspecto mais importante da análise.
} 


\section{Resultados e Discussão}

A Tabela 1 exibe os valores do índice de Gini da distribuição da posse da terra. Pode-se constatar que, de modo geral, esse indicador é mais elevado para os municípios pertencentes à região Norte, destacando-se os municípios de Campos dos Goytacazes, onde ele se situa em torno de 0,800, e também Macaé, Quissamã e São João da Barra, com índices situando-se na faixa de 0,700 a 0,750. Apesar disso, tomando-se os valores calculados por HOFFMANN (1988), para o ano de 1998, pode-se concluir que a distribuição da terra nesses municípios é menos concentrada do que em nível de Brasil, com índice de Gini de 0,843, e, com exceção de Campos dos Goytacazes, apresenta-se semelhante à distribuição da região Sudeste, com índice de Gini de 0,757, e do Rio de Janeiro, com índice de Gini de 0,751.

Tabela 1 - Índice de Gini da distribuição da posse da terra nos os municípios das regiões Norte e Noroeste Fluminense, 1972-1998

\begin{tabular}{lcccccc}
\hline \multirow{2}{*}{ Município } & \multicolumn{7}{c}{ Índice de Gini } \\
\cline { 2 - 7 } & 1972 & 1989 & 1990 & 1991 & 1992 & 1998 \\
\hline Aperibé & - & - & - & - & - & 0,390 \\
B. Jesus do Itabapoana & 0,579 & 0,616 & 0,608 & 0,603 & 0,570 & 0,575 \\
Cambuci & 0,656 & 0,651 & 0,651 & 0,652 & 0,643 & 0,640 \\
C.dos Goytacazes & 0,805 & 0,791 & 0,787 & 0,790 & 0,796 & 0,789 \\
Cardoso Moreira & - & - & - & - & 0,646 & 0,760 \\
Conceição de Macabu & 0,654 & 0,669 & 0,638 & 0,664 & 0,617 & 0,664 \\
Italva & - & 0,632 & 0,626 & 0,624 & 0,616 & 0,637 \\
Itaocara & 0,641 & 0,645 & 0,633 & 0,631 & 0,585 & 0,690 \\
Itaperuna & 0,645 & 0,645 & 0,644 & 0,644 & 0,655 & 0,661 \\
Laje do Muriaé & 0,632 & 0,610 & 0,615 & 0,616 & 0,645 & 0,647 \\
Macaé & 0,749 & 0,729 & 0,719 & 0,718 & 0,720 & 0,731 \\
Miracema & 0,639 & 0,616 & 0,613 & 0,612 & 0,638 & 0,638 \\
Natividade & 0,614 & 0,597 & 0,594 & 0,596 & 0,593 & 0,607 \\
Porciúncula & 0,588 & 0,589 & 0,598 & 0,602 & 0,574 & 0,578 \\
Quissamã & - & - & 0,747 & 0,747 & 0,780 & 0,766 \\
Sto. Antônio de Pádua & 0,604 & 0,587 & 0,586 & 0,586 & 0,584 & 0,583 \\
São Fidélis & 0,644 & 0,638 & 0,646 & 0,645 & 0,636 & 0,647 \\
São João da Barra & 0,765 & 0,732 & 0,728 & 0,730 & 0,704 & 0,721 \\
Varre-Sai & - & - & - & - & 0,330 & 0,542 \\
\hline
\end{tabular}

Fonte: dados da pesquisa. 
A Figura 1, relativa ao ano de 1972, permite visualizar as diferenças entre as duas mesorregiões consideradas ${ }^{3}$. Nela, pode-se observar que valores mais baixos do índice de Gini encontram-se nos municípios da região Noroeste, em geral menores que 0,650, com exceção de Cambuci, até então possuindo o atual município de São José de Ubá como um de seus distritos, que apresentou índice de Gini ligeiramente superior a 0,650.

Figura 1 - Índice de Gini da distribuição da posse da terra nos municípios das regiões Norte e Noroeste Fluminense, 1972.

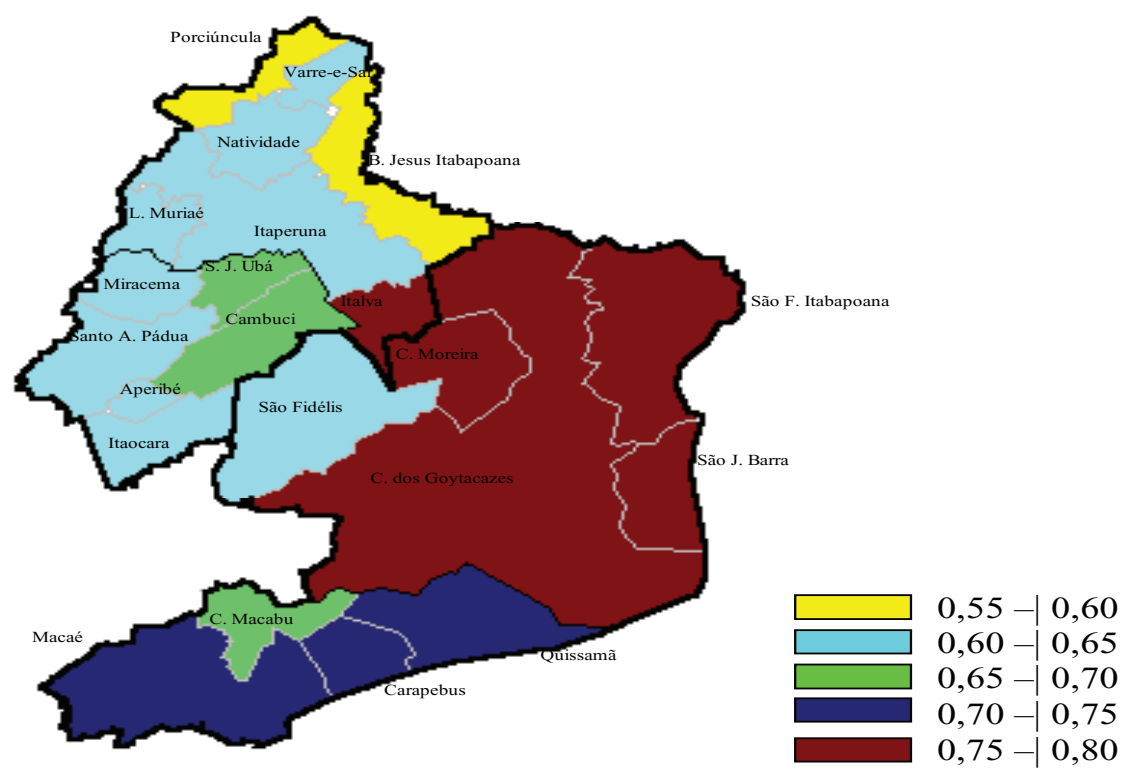

Fonte: dados da pesquisa.

A estrutura agrária da região Norte, mais concentrada e caracterizada pelo latifúndio açucareiro, tem origem no início do século XX, com o advento das grandes usinas, que substituíram o engenho a vapor e alte-

\footnotetext{
${ }^{3} \mathrm{O}$ mapa da figura representa a divisão municipal recente, para possibilitar uma comparação com os dias atuais, e não a divisão do ano de 1972, ao qual ele se refere. Nesse ano, alguns dos municípios retratados no mapa ainda não existiam e, nesse caso, a faixa do índice de Gini indicada para eles é, simplesmente, aquela que foi calculada para os municípios dos quais se emanciparam. Ou seja, assumiu-se que a distribuição da terra nas áreas que atualmente pertencem a esses municípios era, no ano de 1972, equivalente à distribuição da terra dos municípios dos quais se desmembraram.
} 
raram a organização precedente, na qual tinham grande importância os pequenos fornecedores de cana (TOTTI e PEDROSA, 2006).

De todo o modo, pode-se concluir, a partir da convenção estabelecida por CÂMARA (1949), descrita na Tabela 2, que mesmo nos municípios com índice de Gini mais baixos, a maioria dos quais pertencentes à região Noroeste, a distribuição da terra não deve ser entendida como pouco concentrada. Assim, pode-se constatar que os municípios com menor concentração da terra apresentam, no decorrer de todo o período analisado, índices de Gini na faixa de 0,501 a 0,700, o que caracteriza, ainda assim, uma concentração média a forte. As exceções são os municípios de VarreSai e Aperibé, cujos valores do índice de Gini, nos anos de 1992 e 1998, respectivamente, correspondem à concentração fraca a média ${ }^{4}$.

Tabela 2 - Concentração da terra, segundo valores do índice de Gini

\begin{tabular}{cl}
\hline Faixa do índice de Gini & Classificação \\
\hline 0,000 a 0,100 & Concentração nula \\
0,101 a 0,250 & Concentração nula a fraca \\
0,251 a 0,500 & Concentração fraca a média \\
0,501 a 0,700 & Concentração média a forte \\
0,701 a 0,900 & Concentração forte a muito forte \\
0,901 a 1,000 & Concentração muito forte a absoluta \\
\hline
\end{tabular}

Fonte: Câmara (1949)

Pode-se concluir ainda que os casos de concentração mais elevada correspondem aos municípios de Campos dos Goytacazes, Macaé e São João da Barra, cujos valores do índice de Gini, ao longo de todo o período, caracterizam uma distribuição da posse da terra com concentração forte a muito forte. Mesmo Cardoso Moreira, que no período pós-emancipação exibira concentração média a forte, em 1998 já mostra valores do índice de Gini correspondentes a uma concentração forte a muito forte.

\footnotetext{
${ }^{4}$ As informações relativas a esses dois municípios apresentam-se de tal modo dissonantes das demais que recomendem cautela em sua interpretação. Os valores obtidos para o índice de Gini são muito baixos e destoam significativamente daqueles obtidos para os demais municípios. Além disso, como em Varre-Sai o índice de Gini assume, em 1998, valor bem mais elevado, isso indica que a primeira estatística poderia apresentar algum viés decorrente do processo de emancipação do município. Em razão disso, os valores obtidos para os indicadores de distribuição da posse da terra nesses municípios devem ser considerados com alguma ressalva.
} 
A Figura 2 permite observar o comportamento do índice de Gini entre os anos considerados. Nela, pode-se constatar alguma tendência de redução no índice de Gini para os municípios de Cambuci, Campos dos Goytacazes, Macaé, Santo Antônio de Pádua e, principalmente, São João da Barra. Em todos esses casos, a distribuição da terra, ao final do período analisado, apresenta índice de Gini inferior ao apresentado no início do período. Em situação oposta, com tendência de predominante elevação do índice de Gini, encontram-se os municípios de Itaperuna, Quissamã e Laje do Muriaé, além de Cardoso Moreira e Varre-Sai, sendo que, no caso desses dois últimos, a comparação resume-se a apenas dois anos, podendo, ademais, refletir apenas o efeito do período pósemancipação. Em virtude dessas alterações, o índice de Gini, no último ano, apresenta valor mais elevado do que no início do período.

Figura 2 - Comportamento do índice de Gini da distribuição da posse da terra nos municípios das regiões Norte e Noroeste Fluminense: 1972-1998

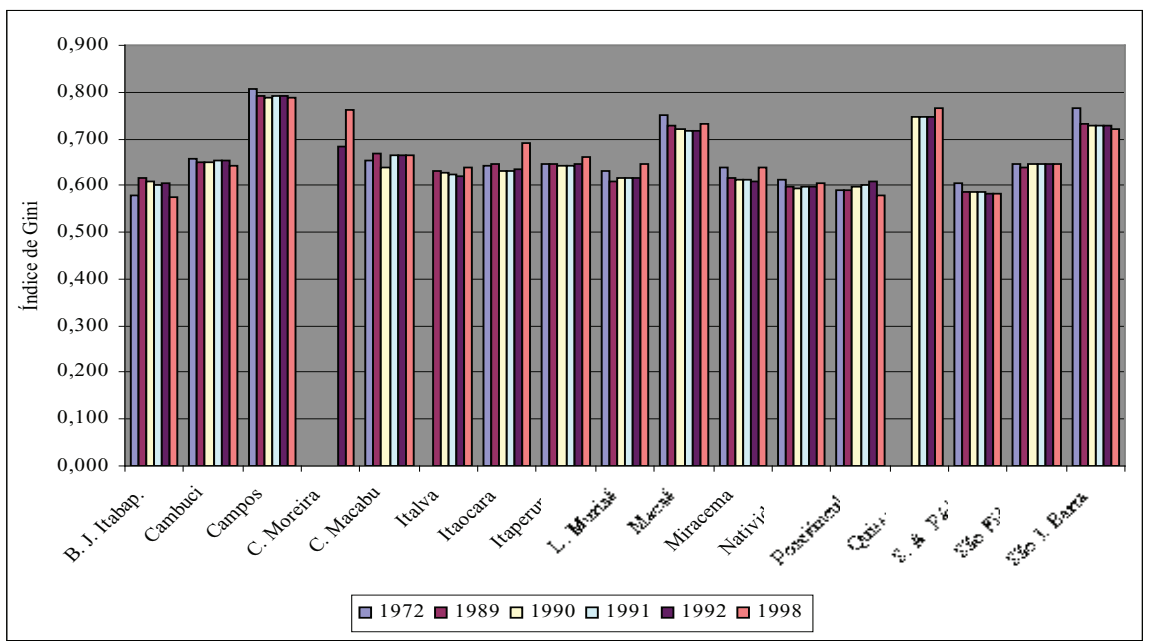

Fonte: dados da pesquisa.

Para os demais municípios não se pode constatar nenhum comportamento predominante do índice de Gini. Além disso, pode-se concluir que, com exceção de Itaocara, cujo índice de Gini ao final do período mostra-se significativamente superior ao valor obtido em 1972, nos demais muni- 
cípios as transformações ocorridas não geraram alterações persistentes nesse indicador. Para todos eles, o índice de Gini, em 1998, tem valor semelhante ao obtido para a distribuição da posse da terra no ano de 1972.

Desse modo, pode-se concluir que, apesar das mudanças observadas, não houve grandes alterações no índice de Gini da distribuição da posse da terra nesses municípios, como pode ser constatado na Figura 3, que faz a distinção dos municípios com base no valor do índice de Gini para o ano de 1998.

Em nível de regiões, análises efetuadas por SIMÕES e SOUZA (2004) e SIMÕES e SOUZA (2005), evidenciaram que a região Noroeste, conquanto apresente índices melhores de distribuição da posse da terra, vêm piorando esses indicadores, principalmente no período de 1970 a 1985. A região Norte, por sua vez, tem apresentado um comportamento estável, com manutenção dos indicadores que revelam sua elevada concentração fundiária. De todo o modo, essas mudanças não foram suficientes para alterar o perfil agrário das regiões. Quando comparada à Figura 1, a Figura 3 revela que a distribuição da posse da terra permanece mais concentrada na região Norte.

Figura 3 - Índice de Gini da distribuição da posse da terra nas regiões Norte e Noroeste Fluminense, 1998

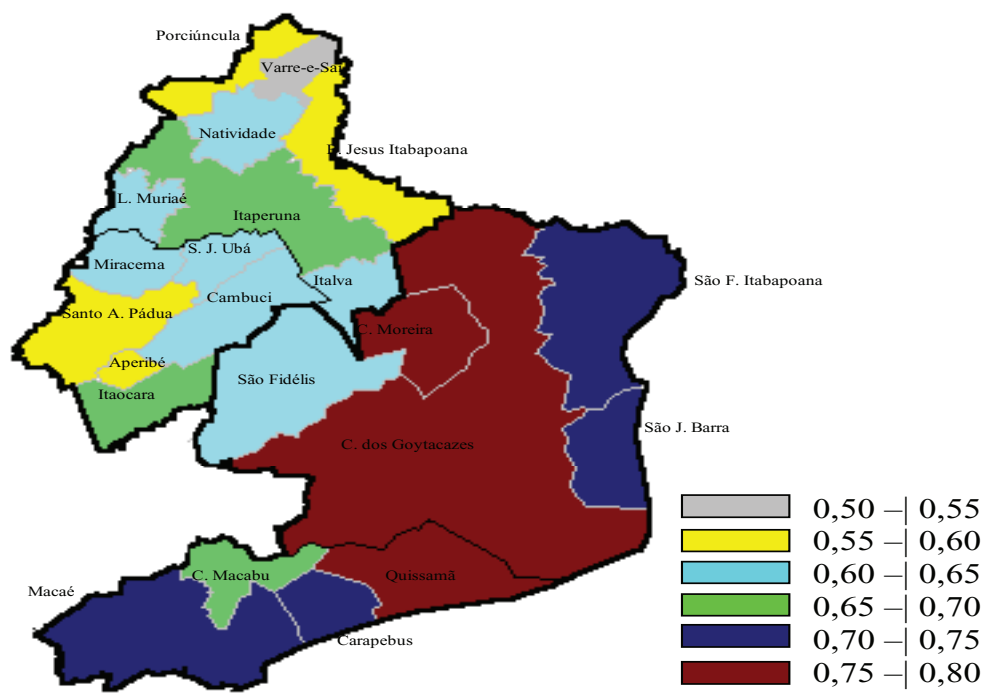

Fonte: dados da pesquisa. 
Na Tabela 3, que apresenta a área média dos imóveis, pode-se observar que esse indicador apresenta-se mais elevado no município de Conceição de Macabú, com valor em torno de 100 hectares, assim como em Quissamã e Macaé, onde a área média está compreendida, na maior parte do período, na faixa de 70 a 80 hectares. Já os municípios de Italva, Itaocara, Santo Antônio de Pádua, São Fidélis e São João da Barra se destacam, entre os demais, por apresentarem as menores áreas médias, que se situam, durante o período estudado, na faixa de 20 a 40 hectares. Em situação intermediária encontram-se todos os demais municípios, com área média compreendida na faixa de 40 a 60 hectares.

Tabela 3 - Área média da distribuição da posse da terra nos municípios das regiões Norte e Noroeste Fluminense, 1972-1998

\begin{tabular}{lcccccc}
\hline \multirow{2}{*}{ Município } & \multicolumn{5}{c}{ Área média (ha) } \\
\cline { 2 - 7 } & 1972 & 1989 & 1990 & 1991 & 1992 & 1998 \\
\hline Aperibé & - & - & - & - & - & 7,50 \\
B. Jesus do Itabapoana & 57,05 & 51,68 & 53,00 & 52,22 & 49,97 & 50,73 \\
Cambuci & 45,28 & 43,72 & 43,17 & 43,11 & 47,12 & 44,11 \\
C.dos Goytacazes & 41,88 & 41,47 & 40,22 & 40,22 & 46,12 & 46,31 \\
Cardoso Moreira & - & - & - & - & 29,17 & 50,31 \\
Conceição de Macabu & 109,81 & 110,29 & 97,79 & 107,13 & 96,23 & 114,77 \\
Italva & - & 33,97 & 32,10 & 32,00 & 32,64 & 31,86 \\
Itaocara & 24,77 & 24,52 & 23,67 & 23,63 & 24,24 & 32,05 \\
Itaperuna & 54,66 & 56,06 & 55,85 & 55,98 & 64,23 & 65,81 \\
Laje do Muriaé & 59,89 & 56,64 & 57,25 & 56,30 & 51,19 & 50,44 \\
Macaé & 95,38 & 71,32 & 68,03 & 67,51 & 76,61 & 75,89 \\
Miracema & 54,60 & 56,38 & 55,21 & 54,38 & 57,85 & 57,02 \\
Natividade & 60,18 & 55,42 & 54,30 & 54,02 & 47,48 & 46,89 \\
Porciúncula & 68,35 & 58,73 & 56,90 & 57,58 & 61,64 & 59,14 \\
Quissamã & - & - & 83,51 & 83,51 & 72,85 & 66,11 \\
Sto. Antônio de Pádua & 31,14 & 29,57 & 28,91 & 28,74 & 31,65 & 29,90 \\
São Fidélis & 39,46 & 37,44 & 37,14 & 36,84 & 33,59 & 33,71 \\
São João da Barra & 32,66 & 27,53 & 26,93 & 26,99 & 26,89 & 27,61 \\
Varre-Sai & - & - & - & - & 52,85 & 45,85 \\
\hline
\end{tabular}

Fonte: dados da pesquisa.

Como pode ser observado na Figura 4, a área média exibiu tendência de declínio ao longo do período nos municípios de Bom Jesus do Ita- 
bapoana, Italva, Laje do Muriaé, Natividade, Quissamã, São Fidélis, São João da Barra e Varre-Sai. Por outro lado, apenas em Itaperuna e Miracema pode-se constatar um comportamento de predominante elevação da área média. Para os demais municípios, o comportamento da área média é irregular, dificultando a identificação de tendências. De todo o modo, pode-se constatar que, com exceção de Campos dos Goytacazes, Cardoso Moreira, Conceição de Macabu e Itaocara, nos demais municípios a área média, ao final do período abordado, apresenta-se inferior ao valor exibido em 1972. Assim, pode-se concluir, a partir desses resultados, que, para a maior parte dos municípios considerados, a área média apresentou-se em declínio durante o período envolvido na análise.

Figura 4 - Comportamento da área média dos imóveis nos municípios das regiões Norte e Noroeste e Fluminense: 1972-1998

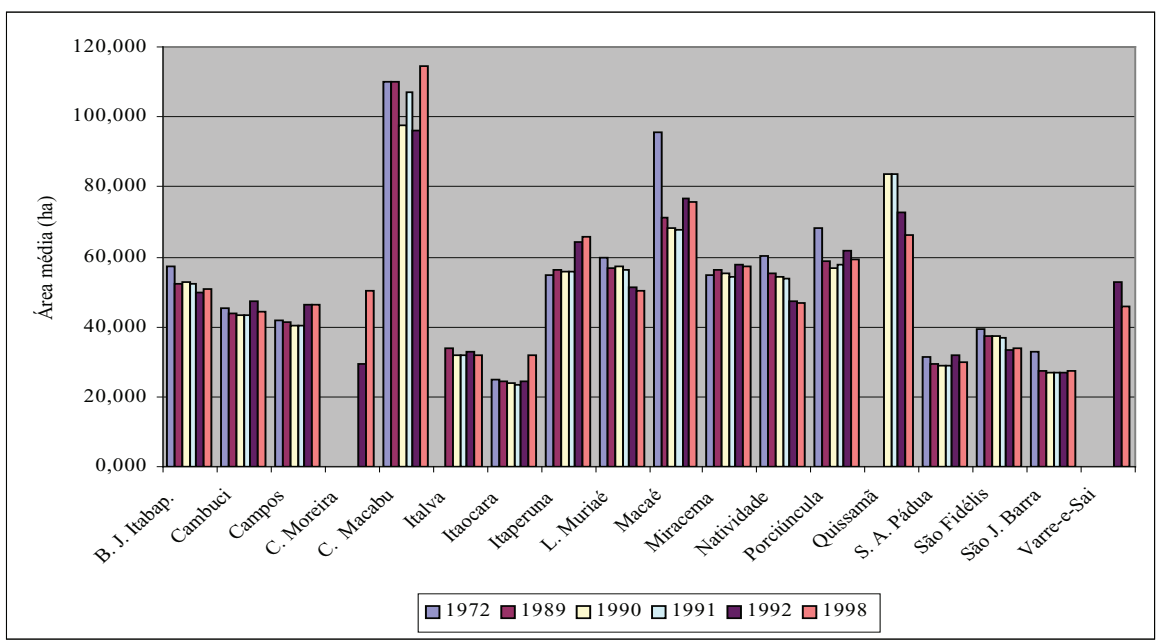

Fonte: dados da pesquisa.

Os valores obtidos para o percentual da área total correspondente aos 5\% maiores imóveis encontram-se na Tabela 4. Pode-se constatar que esse percentual é elevado, situando-se próximo de $60 \%$, nos municípios de Campos dos Goytacazes e Cardoso Moreira, embora, neste último caso, essa constatação refira-se apenas ao ano de 1998. Esse percentual é também elevado, da ordem de $50 \%$, para os municípios de São João da Barra e Macaé, o que, nos dois últimos anos, também se 
aplica a Quissamã. O fato de que esses municípios pertencem à região Norte revela a diferença marcante entre as estruturas fundiárias dessas regiões, já comentada anteriormente. Para os demais municípios, o percentual da área total correspondente aos $5 \%$ maiores imóveis encontrase na faixa de $30 \%$ a $40 \%$.

Tabela 4 - Percentual da área total correspondente aos $5 \%$ maiores imóveis nos municípios das regiões Norte e Noroeste Fluminense, 1972-1998

\begin{tabular}{lcccccc}
\hline \multirow{2}{*}{ Município } & \multicolumn{6}{c}{ Percentual de área dos $5 \%$ maiores } \\
\cline { 2 - 7 } & 1972 & 1989 & 1990 & 1991 & 1992 & 1998 \\
\hline Aperibé & - & - & - & - & - & 9,97 \\
B. Jesus do Itabapoana & 30,33 & 37,95 & 36,84 & 36,43 & 29,93 & 30,75 \\
Cambuci & 39,78 & 38,49 & 38,50 & 38,64 & 39,07 & 38,76 \\
C.dos Goytacazes & 60,81 & 58,44 & 57,65 & 58,04 & 58,82 & 57,24 \\
Cardoso Moreira & - & - & - & - & 44,57 & 59,42 \\
Conceição de Macabu & 38,54 & 40,51 & 34,31 & 39,68 & 29,84 & 36,63 \\
Italva & - & 40,93 & 41,08 & 40,72 & 40,50 & 43,58 \\
Itaocara & 39,91 & 42,04 & 39,91 & 39,84 & 30,80 & 48,30 \\
Itaperuna & 38,86 & 39,65 & 39,55 & 39,63 & 41,60 & 41,63 \\
Laje do Muriaé & 33,31 & 34,05 & 35,14 & 35,57 & 37,01 & 36,86 \\
Macaé & 50,59 & 47,55 & 48,27 & 48,13 & 48,99 & 48,89 \\
Miracema & 29,01 & 29,36 & 29,09 & 29,70 & 30,23 & 30,36 \\
Natividade & 32,99 & 32,21 & 31,40 & 31,40 & 30,68 & 31,90 \\
Porciúncula & 25,80 & 27,59 & 29,22 & 30,11 & 30,46 & 30,38 \\
Quissamã & - & - & 43,75 & 43,75 & 49,88 & 47,48 \\
Sto. Antônio de Pádua & 33,70 & 33,05 & 33,23 & 33,33 & 32,03 & 32,30 \\
São Fidélis & 40,06 & 40,49 & 42,12 & 41,79 & 41,56 & 42,72 \\
São João da Barra & 56,00 & 52,22 & 51,71 & 51,97 & 47,78 & 50,94 \\
Varre-Sai & - & - & - & - & 8,30 & 25,21 \\
\hline
\end{tabular}

Fonte: dados da pesquisa.

Na Figura 5 pode-se constatar que, para um número significativo de municípios, o percentual da área total correspondente aos $5 \%$ maiores imóveis tendeu a se elevar no período. 
Figura 5 - Comportamento do percentual da área correspondente aos $5 \%$ maiores imóveis nos municípios das regiões Norte e Noroeste Fluminense: 1972-1998

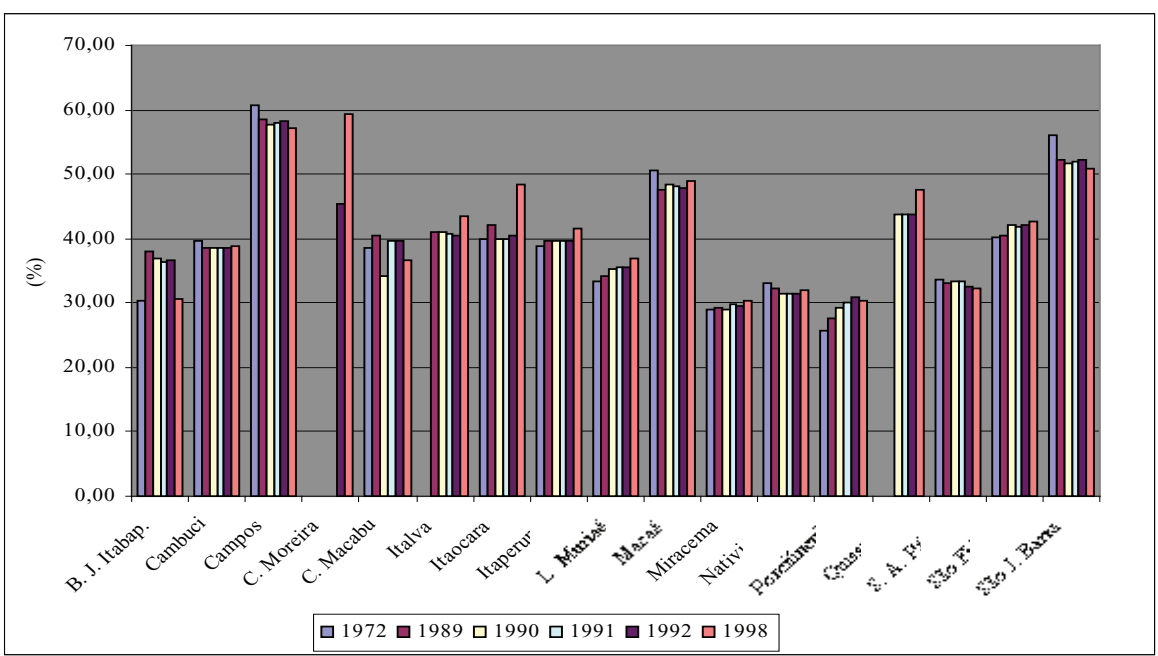

Fonte: dados da pesquisa

Esse é, predominantemente, o comportamento observado em Cardoso Moreira, Itaperuna, Laje do Muriaé, Miracema, Porciúncula, São Fidélis e Varre-Sai. Com exceção de Campos dos Goytacazes, Natividade, Santo Antônio de Pádua e São João da Barra, nos quais esse indicador apresenta tendência declinante, no restante dos municípios sua evolução é mais irregular.

A Tabela 5 apresenta os resultados obtidos para o percentual da área total correspondente aos 50\% menores imóveis. Observa-se que esse percentual é em geral muito baixo, não chegando a representar sequer a $14 \%$ da área total dos imóveis. Em Campos dos Goytacazes e Quissamã, os $50 \%$ menores imóveis ocupam cerca de apenas $4 \%$ da área total. Em São João da Barra e Macaé, também pertencentes à região Norte, esse percentual é relativamente baixo, resultado que reflete o perfil fundiário tipicamente mais concentrado dessa região. 
Tabela 5 - Percentual da área total correspondente aos 50\% menores imóveis nos municípios das regiões Norte e Noroeste Fluminense, 1972-1998

\begin{tabular}{lcccccc}
\hline \multirow{2}{*}{ Município } & \multicolumn{5}{c}{ Percentual de área dos $50 \%$ menores } \\
\cline { 2 - 7 } & 1972 & 1989 & 1990 & 1991 & 1992 & 1998 \\
\hline Aperibé & - & - & - & - & - & 18,44 \\
B. Jesus do Itabapoana & 13,11 & 12,67 & 11,58 & 11,83 & 12,78 & 12,49 \\
Cambuci & 10,33 & 10,24 & 10,24 & 10,25 & 10,47 & 10,75 \\
C.dos Goytacazes & 3,98 & 4,39 & 4,49 & 4,39 & 4,12 & 4,22 \\
Cardoso Moreira & - & - & - & - & 11,82 & 7,53 \\
Conceição de Macabu & 8,92 & 8,29 & 9,22 & 8,53 & 8,75 & 7,26 \\
Italva & - & 12,20 & 12,61 & 12,67 & 13,30 & 12,49 \\
Itaocara & 10,34 & 10,47 & 10,84 & 10,98 & 12,44 & 9,22 \\
Itaperuna & 9,89 & 9,89 & 9,97 & 9,95 & 9,74 & 9,47 \\
Laje do Muriaé & 9,77 & 11,23 & 11,07 & 11,11 & 9,73 & 9,68 \\
Macaé & 5,68 & 7,12 & 7,92 & 7,95 & 7,81 & 7,29 \\
Miracema & 8,46 & 9,20 & 9,30 & 9,54 & 8,64 & 8,57 \\
Natividade & 10,42 & 11,24 & 11,14 & 10,94 & 11,57 & 10,96 \\
Porciúncula & 11,05 & 11,12 & 10,45 & 10,35 & 12,68 & 12,35 \\
Quissamã & - & - & 4,36 & 4,36 & 3,46 & 3,65 \\
Sto. Antônio de Pádua & 13,06 & 13,65 & 13,70 & 13,72 & 13,91 & 13,78 \\
São Fidélis & 11,47 & 11,92 & 11,67 & 11,69 & 12,41 & 11,77 \\
São João da Barra & 5,83 & 6,97 & 7,14 & 7,12 & 7,73 & 7,32 \\
Varre-Sai & - & - & - & - & 17,03 & 13,60 \\
\hline
\end{tabular}

Fonte: dados da pesquisa.

O percentual da área correspondente aos $50 \%$ menores estabelecimentos variou de forma bastante irregular durante o período, como pode ser observado na Figura 6. Pode-se constatar alguma tendência de crescimento desse percentual em Cambuci, Santo Antônio de Pádua, São Fidélis e em São João da Barra, e de declínio em Conceição de Macabu, Itaperuna e Quissamã, além de Cardoso Moreira e Varre-Sai, os quais, entretanto, contam com apenas dois anos para comparação. 
Figura 6 - Comportamento do percentual da área correspondente aos 50\% menores imóveis nos municípios das regiões Norte e Noroeste Fluminense:

1972-1998

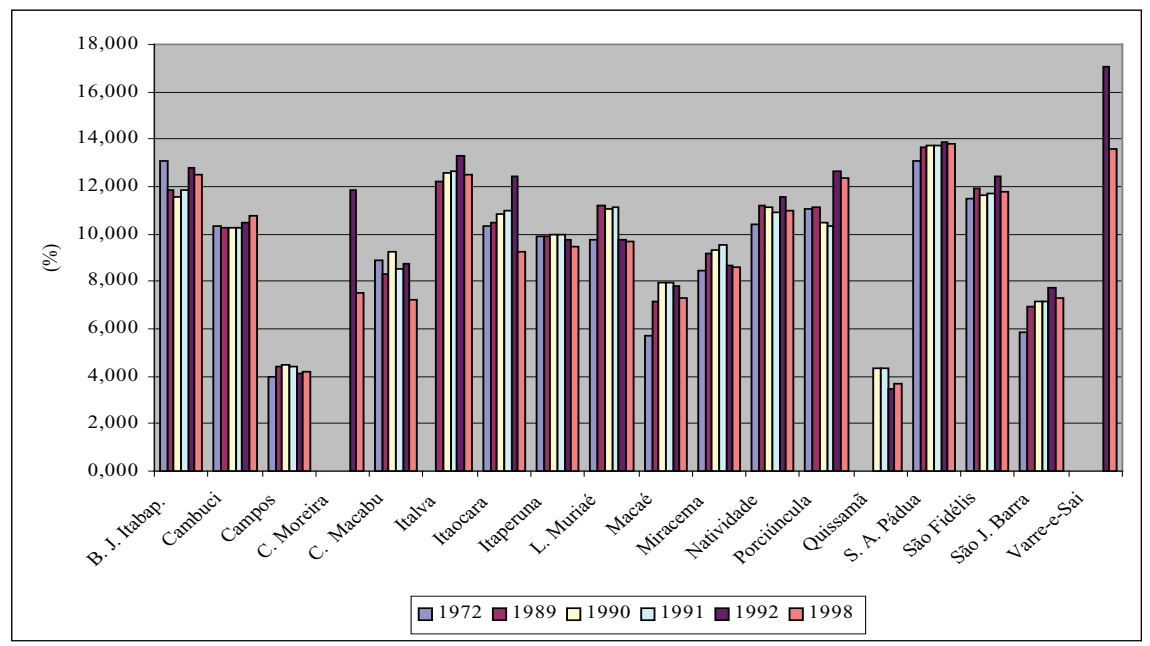

Fonte: dados da pesquisa.

A Tabela 6, que apresenta a variação, entre o início e o final do período analisado, em todos os indicadores considerados, fornece uma visão aproximada e sintética das transformações ocorridas na estrutura fundiária das regiões Norte e Noroeste fluminense. Essa síntese revela a existência de quatro situações distintas quanto ao sentido das alterações ocorridas.

O primeiro grupo, que agrega o maior número de municípios, é caracterizado, de modo geral, por um processo de melhoria na distribuição da posse da terra, com redução no índice de Gini, na área média e no percentual da área correspondente aos 5\% maiores imóveis, concomitante ao aumento no percentual da área dos 50\% menores. É importante destacar que, dentre os elementos desse grupo, constituído por São João da Barra, Santo Antônio de Pádua, Macaé, Cambuci, Porciúncula, Natividade, Bom Jesus do Itabapoana, somente nos três primeiros as alterações ocorridas foram mais significativas, refletindo-se em elevação mais expressiva do índice de Gini.

O segundo grupo, formado pelos municípios de Cardoso Moreira, Itaocara, Itaperuna e Conceição de Macabu, caracteriza-se por sofrer alterações na estrutura fundiária com sentido predominante de concentração da distribuição da posse da terra, com aumento do índice de Gini, da área 
média e do percentual da área correspondente aos 5\% maiores imóveis, associado à redução no percentual da área ocupada pelos $50 \%$ menores. Desse conjunto de municípios, pode-se concluir que apenas em Cardoso Moreira e Itaocara as transformações ocorridas foram mais significativas.

Já os municípios de Varre-Sai, Quissamã, Laje do Muriaé, Italva e São Fidélis, que constituem o terceiro grupo, caracterizam-se por sofrer redução da área média, sem que isso se reverta na melhoria dos demais indicadores. Tal situação parece indicar um processo de subdivisão de imóveis menores, com multiplicação daqueles pertencentes aos extratos inferiores da distribuição, o que apenas contribui para redução da área média, sem afetar positivamente os demais indicadores. Entretanto, nem todos os elementos desse grupo experimentaram alterações expressivas nos indicadores de distribuição da posse da terra, cabendo destacar apenas os casos de Varre-Sai e Quissamã, nos quais o índice de Gini sofreu maiores alterações.

Tabela 6 - Variação nos indicadores da distribuição da posse da terra nos municípios das regiões Norte e Noroeste fluminense entre 1972 e 1998.

\begin{tabular}{lcccc}
\hline Municípios & IG & AM & A5 & A50 \\
\hline São João da Barra & $-0,043$ & $-5,049$ & $-5,067$ & 1,495 \\
Santo Antônio de Pádua & $-0,020$ & $-1,232$ & $-1,397$ & 0,715 \\
Macaé & $-0,019$ & $-19,483$ & $-1,698$ & 1,613 \\
Cambuci & $-0,015$ & $-1,174$ & $-1,013$ & 0,424 \\
Porciúncula & $-0,010$ & $-9,209$ & 4,579 & 1,300 \\
Natividade & $-0,007$ & $-13,299$ & $-1,091$ & 0,533 \\
Bom Jesus do Itabapoana & $-0,004$ & $-6,318$ & 0,426 & $-0,619$ \\
\hline Cardoso Moreira & 0,114 & 21,143 & 14,846 & $-4,296$ \\
Itaocara & 0,049 & 7,281 & 8,393 & $-1,120$ \\
Itaperuna & 0,016 & 11,151 & 2,770 & $-0,419$ \\
Conceição de Macabu & 0,011 & 4,964 & $-1,909$ & $-1,667$ \\
\hline Varre-Sai & 0,212 & $-6,998$ & 16,910 & $-3,425$ \\
Quissamã & 0,019 & $-17,393$ & 3,738 & $-0,706$ \\
Laje do Muriaé & 0,015 & $-9,445$ & 3,556 & $-0,097$ \\
Italva & 0,005 & $-2,116$ & 2,650 & 0,295 \\
São Fidélis & 0,002 & $-5,755$ & 2,654 & 0,296 \\
\hline Campos dos Goytacazes & $-0,016$ & 4,435 & $-3,569$ & 0,239 \\
Miracema & $-0,001$ & 2,421 & 1,347 & 0,116 \\
\hline
\end{tabular}

Obs:IG = índicedeGini; $\mathrm{AM}$ = áreamédia; $\mathrm{A} 5$ = percentualdaáreatotalcorrespondenteaos $5 \%$ maiores estabelecimentos; $\mathrm{e}, \mathrm{A} 50$ = percentualdaáreatotal correspondenteaos $50 \%$ menoresestabelecimentos. Fonte: dados da pesquisa. 
Finalmente, os municípios de Campos dos Goytacazes e Miracema, que compõem o último grupo, caracterizam-se por apresentarem poucas alterações na distribuição da posse da terra no período considerado. Apresentam pequenas alterações nos indicadores, com sentido predominante de redução no índice de Gini, elevação da área média e aumento no percentual da área correspondente aos 50\% menores imóveis.

\section{Conclusões}

Com essa pesquisa, procurou-se realizar uma caracterização do perfil fundiário das regiões Norte e Noroeste fluminense, bem como descrever suas alterações no decorrer do tempo. Os resultados permitiram constatar a presença de diferenças significativas no perfil agrário dessas regiões, com os municípios da região Norte destacando-se por uma distribuição nitidamente mais concentrada do que os da região Noroeste. Esse fato é importante, e deve ser considerado quando da proposição das políticas agrícola e agrária para essas regiões, que, pela distinção apontada, requerem tratamentos diferenciados.

Uma vez que essas regiões apresentam-se também bastante distintas no que diz respeito a aspectos geográficos, é possível que a menor concentração da posse da terra, identificada nos municípios da região Noroeste, não corresponda, necessariamente, a uma menor concentração econômica, em virtude das diferenças de localização geográfica e fertilidade. Maiores estudos são, portanto, necessários para verificar se o grau mais elevado de concentração da posse da terra, verificado na região Norte, corresponde também a uma maior desigualdade econômica entre os imóveis rurais dessa região.

Com exceção mais evidente dos municípios de Cardoso Moreira, Itaocara, Itaperuna e Conceição de Macabu, com alterações com sentido predominante de concentração da distribuição da posse da terra, um número significativo se municípios apresentou, ao final do período, alguma melhora nos indicadores da distribuição da posse da terra, com redução no índice de Gini, na área média e no percentual da área correspondente aos $5 \%$ maiores imóveis, concomitante ao aumento no percentual da área dos $50 \%$ menores. Porém, como essas mudanças foram, em geral, pouco expressivas, pode-se concluir que os municípios das regiões Norte 
e Noroeste fluminense não passaram por alterações significativas na distribuição da posse da terra no período estudado.

Não se pode concluir, portanto, que as políticas que atuaram no período tenham exercido um efeito expressivo e homogêneo sobre a estrutura fundiária dessas regiões. Em particular, tal efeito não pode ser atribuído ao Proálcool, já que não foi constatada, de modo geral, concentração fundiária nos municípios da região Norte, especializados na produção de cana-de-açúcar. Em razão disso, constata-se que, ao final do período, ambas as regiões permanecem com situação semelhante à que apresentavam no início, mantendo-se as diferenças inter-regionais já assinaladas.

\section{Referências bibliográficas}

AZEVEDO, H. J. Uma análise da cadeia produtiva da cana-de-açúcar na região Norte Fluminense. In: PESSANHA, R. M., SILVA NETO, R. (Org.) Economia e desenvolvimento no Norte Fluminense: da cana de açúcar aos royalties do petróleo. Campos dos Goytacazes, RJ: WTC Editor, 2004. 364 p.

CÂMARA, L. A concentração da propriedade agrária no Brasil. Boletim Geográfico, Rio de Janeiro, v. 7, n. 77, p. 516-528, 1949.

CASTRO, P. R. de. Barões e bóias-frias: repensando a questão agrária no Brasil. Rio de janeiro: APEC/Câmara de Estudos e Debates Econômicos e Sociais, 1982. 99p.

CUNHA, M. S. Convergência da distribuição da posse da terra no Brasil, 1970-1995/96. XLI Congresso Brasileiro de Economia e Sociologia Rural. Anais... Passo Fundo, 2003.

GASQUES, J. G., CONCEIÇÃO, J. C. P. R., BASTOS, E. T. Indicadores de estrutura fundiária na Amazônia Legal. XLI Congresso Brasileiro de Economia e Sociologia Rural. Anais... Passo Fundo, 2003.

GRAZIANO DA SILVA, J. (Coord.). Estrutura agrária e produção de subsistência na agricultura brasileira. 2.ed. São Paulo: Hucitec, 1980. 240p.

HOFFMANN, R. A estrutura fundiária no Brasil de acordo com o cadastro do INCRA: 1967 a 1998. Convênio INCRA/UNICAMP, 1998. http:// www.eco.unicamp.br/projetos/rurbano/textos/pesquiss/fundiaria.html 
HOFFMANN, R. Estimação da desigualdade dentro de estratos no cálculo do índice de Gini e redundância. Pesquisa e Planejamento Econômico, Rio de Janeiro, v. 9, n. 3, p. 719-738, dez.1979.

INCRA - Instituto Nacional de Colonização e Reforma Agrária. Estatísticas Cadastrais. Recadastramento, 1972. Brasília, Ministério da Agricultura, 1974.

INCRA - Instituto Nacional de Colonização e Reforma Agrária. Estatísticas Cadastrais, 1992. Brasília, Ministério da Agricultura, 1974.

INCRA - Instituto Nacional de Colonização e Reforma Agrária. Estatísticas Cadastrais, 1998. Brasília, Ministério da Agricultura, 1974.

INCRA - Instituto Nacional de Colonização e Reforma Agrária. Estatísticas Cadastrais Anuais, 1989. Brasília, Ministério da Agricultura, 1989.

INCRA - Instituto Nacional de Colonização e Reforma Agrária. Estatísticas Cadastrais Anuais, 1990. Brasília, Ministério da Agricultura, 1990.

INCRA - Instituto Nacional de Colonização e Reforma Agrária. Estatísticas Cadastrais Anuais, 1991. Brasília, Ministério da Agricultura, 1991. MARTINE, G., BESKOW, P. R. O modelo, os instrumentos e as transformações na estrutura de produção agrícola. In: MARTINE, G., GARCIA, R. C. (Orgs.). Os impactos sociais da modernização agrícola. São Paulo: Caetés, 1987. p. 19-39

SAES, M. S. M., NAKAZONE, D. Estudo da competitividade de cadeias integradas no Brasil: impactos das zonas de livre comércio (cadeia café). Campinas: UNICAMP-IE-NEIT, 2002. 133p. (Nota Técnica Final)

SIMOES A.P., SOUZA P. M. A Distribuição da terra nas regiões Norte e Noroeste do Estado do Rio de Janeiro: 1970 a 1995. Anais XLII Congresso Nacional Economia e Sociologia Rural. Anais... Cuiabá, 2004 (CD-ROM).

SIMOES A.P., SOUZA P. M. Análise dos financiamentos agrícolas nas regiões Norte e Noroeste Fluminense: 1970 a 1980. XLIII Congresso Nacional Economia e Sociologia Rural. Anais ... Ribeirão Preto, 2005 (CD-ROM).

SOUZA, P. M., LIMA, J. E. A distribuição da terra no Brasil e nas Unidades da Federação, 1970-95/96. Revista Econômica do Nordeste. Fortaleza: , v.34, n.1, p.113 - 132, 2003. 
SOUZA, P. M., PONCIANO, N. J., MATA, H. T. C., DETMANN, E. Questão agrária e desenvolvimento econômico e social nas regiões Norte e Noroeste fluminense. Revista de Economia e Agronegócio, Viçosa, v. 2, n.3, 2004, p. 383-408.

TOTTI, M. E. F., PEDROSA, P. Região Norte Fluminense: terra de contrates. In: CARVALHO, A. M., TOTTI, M. E. F. Formação histórica e econômica do norte fluminense. Rio de Janeiro: Garamond, 2006. 328p.

Recebido em março de 2003 e revisto em julho de 2006. 